\section{A Eulogy for Dr. Setti S. Rengachary, 1937-2008}

The fraternity of Indian-American neurosurgeons is deeply grieved by the death of Dr. Setti S. Rengachary, M.D. who reached significant milestones as an academic neurosurgeon and as an expert in complex adult spine neurosurgery. He is remembered particularly for his neurosurgical textbooks, Neurosurgery and Principles of Neurosurgery, which are used for reference throughout the world. He specialized in spinal reconstruction and the treatment of spinal trauma; he also practiced general neurosurgery and always found time to read and publish scientific articles, a passion he nurtured over the years.

Dr. Setti Rengachary was born on October 4, 1937 to Setti Subiyer and Lakshmi Ammal. After spending the first four years of his life in Palam Cottah, he moved when his father started a saree business in Madurai. Dr. Rengachary was the only one of his siblings who chose medicine as a career and it was an uphill struggle for him to reach his goal especially after his father's business failed. He often remembered the academic struggle he had as a sixth-grade student when he had serious difficulty learning certain subjects. However, with dedicated hard work and discipline, he improved in school eventually reaching the head of the class; he also tutored students younger and older than himself! He studied at St. Mary's High School in Madurai, where he was regarded as a bright and humble student.

He subsequently went to Madurai College and Medical College for his MBBS. He emerged as the top student of the graduating class of 1960 . He then completed a straight surgical internship at the State University of New York in Syracuse, New York and followed this with a fellowship at Harvard Medical School and a residency in neurosurgery at the University of Kansas Medical Center. He also graduated with a degree in anatomy from the University of Kansas in 1969 and was a member of the Cajal Club and American Association of Anatomists, a testimony to his unflinching interest in neuroanatomy. After finishing his neurosurgical residency, he worked at the Veterans Administration Medical Center in Kansas City, Missouri as Chief of Neurosurgery from 1971 to 1989 and was also a member of the academic division of the Department of Neurosurgery at the University of Kansas Medical Center. He was certified by the American Board of Neurological Surgery in 1973 and was licensed to practice medicine in five states in the U.S.: Kansas, Michigan, Minnesota, Missouri, and Virginia. Dr. Rengachary was also a Fellow of the Royal College of Surgeons of Canada.

He subsequently served as a professor of neurosurgery at the Universities of Kansas, Missouri, Minnesota, and Wayne State University. While serving as the Associate Chairman of the Department of Neurosurgery at Wayne State, he also maintained clinical commitments with Detroit Receiving Hospital, Harper University Hospital, Sinai-Grace Hospital, Huron Valley-Sinai Hospital, and Children's Hospital of Michigan, all in Detroit, Michigan, as well as the POH Medical Center in Pontiac, Michigan and St. Mary Mercy Hospital in Livonia, Michigan. His penchant for teaching grew over the decades, culminating in 1999 as the recipient of the Excellence in Teaching Award for the School of Medicine at Wayne State. His name was included in the biographical listings of Personalities of America, Men of Achievement, International Book of Honor, Who's Who in the Midwest, Two Thousand Notable Americans, and Community Leaders in America. Also, The Advanced Technology and Marketing Group selected Dr. Rengachary as its Physician of the Year in 2002.

His major research interest was the biomechanics of the spine. To this effect, Dr. Rengachary was an Adjunct Professor of Mechanical Engineering at Michigan Technological University in Houghton, Michigan. Another area of research was trauma, where he worked on National Institute of Health projects on early hemicraniectomy in severe, traumatic brain injury and also a HeADDFIRST study on hemicraniectomy and durotomy upon deterioration from infraction. He also engaged in corporate-based research involving systems for anterior cervical locking plates and lumbar peritoneal shunts.

Dr. Rengachary was a member of many societies including the American Medical Association, the Congress of Neurological Surgeons, the American Association of Neurological Surgeons, the American Association of Advancement of Science, the Neuroscience Society, the North American Spine Society, the Michigan Association of Neurological Surgeons, the Michigan State Medical Society, the Wayne County Medical Society, and the American Association of Anatomists. He was a Colonel in the U.S. Army Reserve, stationed at the 410th Evacuation Hospital in Topeka, Kansas. He was called upon for active duty to serve as a neurosurgeon in the 89th Arcom, 410th Evacuation Hospital during Operation Desert Storm where he was stationed at Hafar-al-Batin, Saudi Arabia, approximately $30 \mathrm{~km}$ away from the Iraqi border. He always enjoyed working at the Veterans Affairs' hospitals, and he taught an annual spinal course at the Uniformed Services University of the Health Sciences in Bethesda, Maryland from 1999 until his retirement in 2007.

Dr. Rengachary's daughter Usha recollects that he was always interested in reading the history of science, 
which explains his activity in the American Association of Neurological Surgeons in the history of neurosurgery serving as secretary, treasurer, and chairman at different times. I had the unique privilege of co-authoring several peer-reviewed articles on the history of neurosurgery, which were published in reputed journals such as Neurosurgical FOCUS, Neurosurgery, Surgical Neurology, and The Journal of Neurosurgery with our final collaboration documenting the influence Elihu Yale's philanthropy had on the development of neurosurgery in both India and the U.S. Dr. Rengachary's method of procuring and perusing each and every possible reference and his fastidious preparation of the manuscripts was a true testament to his love of research and the exploration of medical history. He would spend long hours in his office reading and writing about various neurosurgical topics, always patient and willing to explain topics to me or any other interested individual. I will hold these cherished memories close to my heart.

Dr. Rengachary was always close to his family; he relished an Indian meal anytime and spoke in chaste Tamil whenever he could. His wife Dhana was an obstetrician/gynecologist and they had two children together: a daughter Usha who was born in 1968 and a son Dave who was born in 1974. After being diagnosed with metastatic carcinoma requiring chemotherapy, Dr. Setti S. Rengachary finally succumbed to complications from cancer on December 12, 2008 leaving his family, friends, co-workers, and collaborators in deep sorrow.
When he retired from Wayne State in 2007 because of these health concerns, I asked him for a message to the Indian neurosurgical community and he told me:

"Indian neurosurgeons must take an active interest in basic neurosciences, nurture teaching, and learning as a combinatorial process and keep up with the emerging technology."

A great teacher and visionary, Dr. Rengachary authored close to 100 peer-reviewed journal articles and over 75 book chapters, in addition to numerous invited editorial comments, book reviews, and his own textbooks. In a handwritten letter dated November 20, 2008, he wrote to me:

"It may sound simple and elementary, but there is no substitute for constant reading and learning."

As an astute clinician, avid reader, and affable surgeon, Dr. Setti Rengachary has left indelible personal impressions on numerous residents and countless neurosurgical colleagues.

On behalf of the neurosurgical community of India, I extend my heartfelt sympathies to his wife Dhana, his children Usha and Dave, and the rest of his family. Personally, this is an irreplaceable loss. I will miss him tremendously, as I have lost a great teacher and guide. May his soul rest in peace.

\section{Sunil Manjila}

Department of Neurosurgery, Wayne State University School of Medicine, Detroit, Mich, USA. E-mail: sunil.manjila@gmail.com 